\title{
Relation between Job Stress and Oxidative Stress Biomarkers among Nurses in Zagazig University Hospitals
}

\author{
Amira Shawally Mohamed $\stackrel{-1}{1}$; Mahmoud Elsayed El-Saadawy ${ }^{2}$; Naema El-laithy Soliman²; Dalia \\ $\underline{\text { Abdalla EL-shafei }^{2}}$ \\ ${ }^{1}$ community and public health department, faculty of medicine, zagazig university \\ ${ }^{2}$ Community, Environmental and Occupational Medicine department, Faculty of Medicine, Zagazig \\ University
}

\begin{abstract}
Background: Nursing is highly demanding and stressful profession. Job stress was found to be a stronger predictor of oxidative stress activity causing elevation of blood oxidative biomarkers. This work aimed to improve mental and psychological health of nurses through identification of prevalence of work stress among nurses at Zagazig university hospitals (ZUHs) and assess the association between work stress and blood oxidative biomarkers. Methods: A comparative cross-sectional study was conducted among 40 nurses and 40 administrative workers at ZUHs. Both two groups were subjected to a structured questionnaire about sociodemographic data and occupational history and two standardized questionnaires about job stress followed by laboratory investigations to measure blood oxidative biomarkers (Malonaldehyde MDA \& Superoxide dismutase SOD). Results: This study showed that job stress and its level were significantly higher among nurses compared to their controls. this study indicated that prevalence of job stress in nurses at ZUHs was $85.0 \%$ compared to $22.5 \%$ in administrative controls where $65.0 \%$ and $20.0 \%$ of them had severe and moderate stress compared to $7.5 \%$ and $15.0 \%$ among controls. Furthermore, this study showed significantly high level of both blood oxidative biomarkers as both levels of MDA, [ Median (3.18) $\mu \mathrm{mol} / \mathrm{ml}]$ and SOD, $[\mathrm{X} \pm \mathrm{SD}: 4.27 \pm 0.40 \mathrm{U} / \mathrm{ml}]$ were significantly higher among nurses compared to their controls Conclusion: Job stress is realistic and widespread phenomena among nurses in ZUHs that have devastating consequences on nurse's health thus, effective preventive strategies should be designed and implemented.
\end{abstract}

Keywords: Job stress; Blood Oxidative biomarkers; Nurses

\section{INTRODUCTION}

$\mathrm{J}$ ob stress is rapidly emerging as the single greatest cause of work-related disease and injury, globally stress-related conditions is expected to rise over this decade such that by 2020, depression and anxiety disorders, including stress-related health conditions, will be second only to ischemic heart disease in prevalence. The epidemiological evidence indicates that job stress is rapidly emerging as the single greatest cause of work-related disease and injury [1].

During the last decade, there has been increasing recognition of the stress experienced by hospital nursing staff [2]. Nurses in parts of a hospital are regular, sympathetic, and interested people when they enter the nursing profession; after a few years of working and facing a lot of occupational stress, they become fatigued and tend to withdraw from their work [3].

Job stress in nursing is of global concern as nursing staff is exposed to high physical and psychosocial work load. Patients' needs and safety, long shifts, work overload, workrelated conflicts, shortage of staff, conflicts with supervisors, bias, and lack of organizational support are stressful factors in nursing [4]. In Egypt health care sector facing a lot of challenges as inadequate expenditure on health inefficient management of the health system at Ministry of Health $(\mathrm{MOH})$ level, Shortcomings in human resources include low capacities and skills, 
mal-distribution of physicians across geographic regions and specialties and insufficient salaries and incentives. Additionally, the health facilities' infrastructure (building, furniture and maintenance) is deteriorating services all of this is considered as job stressor to all health care worker specially nurses [5].

Nursing is highly stressful and demanding profession that is associated with decreased creativity and job satisfaction, lower rate of appropriate decision making, decrease quality of care, increased errors, decreased motivation, depression, detachment, decreased mental and physical well-being, sleep disorders, depression and absenteeism [6].

Oxidative stress is a term used to describe various hazardous processes resulting from an imbalance between the excessive formation of reactive oxygen species ROS and/or reactive nitrogen species RNS and limited antioxidant defenses [7]. Most frequently occurring radicals in biological systems are reactive oxygen species (ROS) and reactive nitrogen species (RNS). Both are generated by the tightly regulated enzymes, nicotinamide adenine dinucleotide phosphate oxidase isoforms and nitric oxide synthases. Overproduction of ROS and RNS results in oxidative stress, a state which is responsible for the damage to cell macromolecules including lipids, proteins and DNA [8].

Generally, Job or life stress especially chronic stress was found to be a stronger predictor of oxidative stress activity than other established oxidant-promoting factors such as cigarette smoking, alcohol consumption, poor diet and exposure to ultraviolet radiation causing elevation of blood biomarkers of oxidative stress [9].

The need to study job stress among has become more important in last year's due to higher rates of trauma patients, increased health care demand and disturbed work conditions. Moreover, the protection of nurses against job stress is an occupational health priority to reduce the negative impacts of this stress on nurse's health and the quality of patient care. Only few studies have been carried out in Egypt to investigate job stress and its relation to blood oxidative biomarkers among nurses. So, studying the prevalence and the associated risk factors of job stress and its relation to oxidative biomarker among nurses in $\mathrm{ZUHs}$ is considered an important topic of research.

Aim of the study: improving mental and psychological health of nurses

Objectives: to asses prevalence of work stress among nurses at ZUHs and to assess the association between work stress and blood oxidative biomarkers.

\section{METHODS}

Study design and settings: A comparative cross section study was conducted at Zagazig university hospitals, Sharkia governorate in the period from April 2018 to February 2019

\section{Target groups:}

group $\square$ : nurses working in ZUHs

group $\square$ :_administrative workers at ZUHs. Both groups were working more than 1-year, non-smokers, non-pregnant and free of recent infectious diseases or history of chronic illness, malignancy or psychiatric disorders.

Sample size: calculated through Open EPI, according to the following collected data: The mean of malondialdehyde MDA level among nurses was $3.2 \pm(2.16) \mu \mathrm{mol} / \mathrm{l}$ and among control group was 2.24 $\pm(0.1) \mu \mathrm{mol} / \mathrm{l}$ [10]. the power of precision was $80 \%$, and the confidence interval was $95 \%$, so the total sample size in both groups was 80 participants (40 nurses and 40 workers)

Sample technique: Regarding nurses: first, we had a list of all clinical departments and units of ZUHs, then we had list of numbers of nurses working in these departments, then we proportional allocated the sample size (40 nurses) between the different departments according to the percentage of their total in each department from the total number of nurses. As regarding sample selection of the other group of administrative workers, it was carried out by using simple random sample technique.

Data collection: All participants in the study were subjected to a structured questionnaire which was used to collect information about Socio-demographic data such as age, sex, marital status, education, residence, number of children, and age of the youngest child. Moreover, asking about practicing exercise, hobbies, Social support, Sleep cycle, and Caffeine intake per day. Occupational history such as, work Department, current position, years of experience, day or rotating shift and work hours per week. 
Two standardized questionnaires about job stress:

First: Job content questionnaire using Demand Control Model. It is a 14-item questionnaire used to measure psychological job demands and decision latitude (control) rated on a 4-point Likert scale (strongly disagree (1), disagree (2), agree (3), and strongly agree (4)). It is comprised of job demands (5 items) and job control (9 items) comprising decision authority (3 items) and skill discretion (6 items). The job strain index, which is calculated as job demands divided by job control, has been used as an indicator of job strain, with higher scores indicating greater strain [11].

Second: The International Stress Management Association (ISMA)To assess stress level, it includes 25 questions answered by yes " 1 point" and no " 0 point" so according to the total score (25), the stress levels classified into: 4 points or less (mild stress), 5 - 13 points (moderate stress) and 14 points or more (severe stress)[12].

Laboratory investigations were done for both groups by measuring MDA to assess oxidative stress status and Superoxide dismutase (SOD) activity to assess antioxidant status. $4 \mathrm{ml}$ venous blood were collected and divided into two halves. Half of the blood collected in plain glass tubes and was left to clot; serum was obtained to measure Lipid Peroxide (Malondialdehyde). The other half of the blood collected into tubes containing potassium Ethylenediaminetetraacetic acid (k-EDTA) for measuring of SOD. MDA was measured according to the method of Ohkawa et al. [13] which based on reaction between MDA and thiobarbituric acid. MDA level was determined by thiobarbituric acid reactive substances (TBARS) in serum and the reference range of MDA is $0.12-1.71$ $\mathrm{nmol} / \mathrm{ml}$. SOD was assayed by spectrophotometry following the method originally developed by Nishikimi et al., [14] and then modified by Kakkar et al., [15], which relies on the ability of the enzyme to inhibit the phenazine methosulphate-mediated reduction of nitroblue tetrazolium dye, and the reference range of SOD was 3.00-3.82 $\mathrm{U} / \mathrm{ml} /$ hematocrit $\times 100$. Gonzales et al. [16]
Data management: The collected data were entered, checked and statistically analyzed using SPSS program (Statistical Package for Social Science) version 22.0 [17]. For the statistical calculations, data coding was done, and qualitative data were represented as frequencies and percentages, Chi square test or fisher exact was used to calculate difference between qualitative variables. Quantitative data were presented as median and compared using student's t-test and Mann-Whitney-U test. Risk factors were estimated by logistic regression analysis. The test results were considered significant when $\mathrm{p}$-value $\leq 0.05$.

\section{Ethical Considerations:}

All procedures followed were in accordance with the ethical standards of the responsible committee on human experimentation (institutional and national) and with the Helsinki Declaration of 1975 , as revised in 2000 [18]. Institutional Review Board (IRB) of the Faculty of Medicine, Zagazig University approved the study protocol (No. 2761). An informed consent was obtained from all participants of this study and they were told about the aim of the study, and were informed that the data would be used for scientific purposes only.

\section{RESULTS}

Results showed that nurses' group and their controls were comparable as regard their sociodemographic data as they were matched regarding age, sex, number of children, age of youngest child at home, education and residence. There were statistically significant differences among both groups regarding caffeine intake, sleep cycle and hobbies as nurses drunk excessive caffeine to be able to stay up at night shifts so they were more day sleepers with less hobbies than their controls. The current study indicated that $10.0 \%$, $30.0 \%, 30.0 \%, 30.0 \%$ of participant nurses were working at Outpatient clinic, Internal medicine \&pediatric, General \& special surgery and ICU \& Emergency departments respectively.

Administrative workers considered not suffering from job stress as nurses due to nature of their work as all administrative workers had fixed day shifts compared to only $10.0 \%$ of nurses as the rest $90.0 \%$ of 
nurses had rotating shifts and all administrative workers had less than 48 working hours /week while $90.0 \%$ nurses had more than 48 working hours /week that ensuring that nursing is highly exhausted and time consuming profession Figure 1\&2. Moreover, this approved later by job content questionnaire as administrative workers had low job demands and high job control.

Table 1. illustrated that there were high statistical differences between nurses and their controls as regards job demand, job control and job strain as nurses suffered from high job demand $(\mathrm{X} \pm \mathrm{SD}=17.50 \pm 3.7)$ with low job control $(\mathrm{X} \pm \mathrm{SD}=14.87 \pm 7.69)$ causing higher job strain score $(\mathrm{X} \pm \mathrm{SD}=1.53 \pm 0.76)$ compared to $\mathrm{X} \pm \mathrm{SD}$ of $(5.52 \pm 1.33)$, $(33.3 \pm 3.59)$ and $(0.16 \pm 0.04)$ respectively among their controls.

Table 2. showed that $85.0 \%$ of nurses suffered from stress compared to $22.5 \%$ in their controls, where $65.0 \%$ and $20.0 \%$ of the studied nurses suffered from severe and moderate stress compared to $7.5 \%$ and $15.0 \%$ respectively among their controls, while
$15.0 \%$ of nurses had mild or no stress compared to $77.5 \%$ in their controls with high statistically significant.

Table 3. showed the most significant predictors for job stress in this study were nurses servicing more than 10 patients /shift, working in Surgery, ICU and Emergency departments followed by being female nurse working more than 48-60hours /week with rotating shifts.

Table 4. indicated that a high statistically significant difference among both nurses group and their controls as regards level of MDA and statistically significant difference as regards level SOD which were higher among nurses than their controls. Moreover, Table (5) showed that both levels of MDA, $[\mathrm{X} \pm \mathrm{SD} \quad$ (range): $3.19 \pm \quad 0.87 \quad(1.17-$ 4.37) $\mu \mathrm{mol} / \mathrm{ml}]$ and SOD, $[\mathrm{X} \pm \mathrm{SD}$ (range): $4.39 \pm 0.37(3.79$ - 4.99) $\mathrm{U} / \mathrm{ml}]$ were significantly higher among nurses with severe stress compared to nurses with moderate and mild or no stress.

Table 1. Difference in job stress among both studied groups

\begin{tabular}{|l|c|c|c|c|}
\hline Job stress (Mean \pm SD): & $\begin{array}{c}\text { Group I } \\
\text { (Nurses) } \\
\mathbf{N}=\mathbf{4 0}\end{array}$ & $\begin{array}{c}\text { Group II } \\
\text { (Workers) } \\
\mathbf{N = 4 0}\end{array}$ & T-test & P value \\
\hline Job demand & $17.50 \pm 3.7$ & $5.52 \pm 1.33$ & 18.9 & $0.000^{*}$ \\
\hline Job control & $14.87 \pm 7.69$ & $33.3 \pm 3.59$ & 13.7 & $0.000^{*}$ \\
\hline Job strain score & $1.53 \pm 0.76$ & $0.16 \pm 0.04$ & 11.2 & $0.000^{*}$ \\
\hline
\end{tabular}

*:Pvalue $<0.001$ is high significant

Table 2. Difference in job stress level scale among both studied groups.

\begin{tabular}{|c|c|c|c|c|c|c|}
\hline \multirow[t]{2}{*}{ Variables } & \multicolumn{2}{|c|}{$\begin{array}{c}\text { Group I } \\
\text { (Nurses) } \\
\mathbf{N}=\mathbf{4 0}\end{array}$} & \multicolumn{2}{|c|}{$\begin{array}{c}\text { Group II } \\
\text { (Workers) } \\
\mathbf{N}=\mathbf{4 0}\end{array}$} & \multirow[t]{2}{*}{$X^{2}$} & \multirow[t]{2}{*}{$P$ value } \\
\hline & $\mathbf{N}$ & $\%$ & $\mathbf{N}$ & $\%$ & & \\
\hline $\begin{array}{l}\text { Job stress level } \\
\text { Mild or no } \\
\text { Moderate } \\
\text { Severe }\end{array}$ & $\begin{array}{c}6 \\
8 \\
26\end{array}$ & $\begin{array}{l}15.0 \\
20.0 \\
60.0\end{array}$ & $\begin{array}{c}31 \\
6 \\
3\end{array}$ & $\begin{array}{c}77.5 \\
15.0 \\
7.5\end{array}$ & 37.05 & $0.000 * *$ \\
\hline
\end{tabular}

**: $\mathbf{P}$-value $<0.001$ is high significant 
Table 3. Logistic regression analysis for significant predictors of job stress among the participant nurses:

\begin{tabular}{|l|l|l|l|l|}
\hline \multicolumn{1}{|c|}{ Variable } & B & S.E. & Wald & P value \\
\hline $\begin{array}{l}\text { Nurses serviced more than 10 patients } \\
\text { per shift. }\end{array}$ & 3.4 & 1.01 & 15.4 & 0.01 \\
\hline $\begin{array}{l}\text { Nurses worked in Surgery- ICU\& } \\
\text { emergency department }\end{array}$ & 3.1 & 0.99 & 11.2 & 0.03 \\
\hline $\begin{array}{l}\text { female nurses } \\
\text { Nurses worked (48-60) hours/week }\end{array}$ & 2.39 & 0.603 & 9.4 & 0.04 \\
\hline Nurses with rotating shift work & 2.39 & 0.603 & 9.4 & 0.04 \\
\hline
\end{tabular}

Table 4. Difference in Blood oxidative biomarkers among both studied groups.

\begin{tabular}{|c|c|c|c|c|}
\hline $\begin{array}{l}\text { Blood Oxidative } \\
\text { Biomarkers }\end{array}$ & $\begin{array}{l}\text { Group I } \\
\text { (Nurses) }\end{array}$ & $\begin{array}{c}\text { Group II } \\
\text { (Workers) }\end{array}$ & $\begin{array}{l}\text { t-test } \\
\text { MW }\end{array}$ & P value \\
\hline $\begin{array}{l}\text { MDA } \quad \mu \mathrm{mol} / \mathrm{ml} \\
\text { Median } \\
\text { Range }\end{array}$ & $\begin{array}{c}3.18 \\
1.17-4.37\end{array}$ & $\begin{array}{c}1.25 \\
0.60-1.6\end{array}$ & $55.50 *$ & $0.000 * *$ \\
\hline $\begin{array}{l}\text { SOD } \\
\mathrm{X} \pm \mathrm{SD} \\
\text { Range }\end{array}$ & $\begin{array}{l}4.27 \pm 0.40 \\
3.60-4.99\end{array}$ & $\begin{array}{l}3.50 \pm 0.42 \\
3.00-3.95\end{array}$ & 8.2 & $0.01 *$ \\
\hline
\end{tabular}

*: $\mathbf{P}$-value $<0.05$ is significant $* *$ : $\mathbf{P}$-value $<0.001$ is high significant

Table 5. Relation between job stress and oxidative stress biomarker among studied nurses (group I).

*: $\mathbf{P}$-value $<0.05$ is significant

\begin{tabular}{|c|c|c|c|c|c|}
\hline \multirow{2}{*}{$\begin{array}{l}\text { Blood oxidative } \\
\text { biomarkers }\end{array}$} & \multicolumn{3}{|c|}{ Job stress level } & \multirow[b]{2}{*}{ F-test } & \multirow[b]{2}{*}{$P$ value } \\
\hline & $\begin{array}{l}\text { Mild or no } \\
\quad \mathrm{N}=6\end{array}$ & $\begin{array}{c}\text { Moderate } \\
\mathbf{N}=\mathbf{8}\end{array}$ & $\begin{array}{l}\text { Severe } \\
\mathrm{N}=26\end{array}$ & & \\
\hline $\begin{array}{lr}\text { MDA } & \mu \mathrm{mol} / \mathrm{ml} \\
\mathrm{X} \pm \mathrm{SD} & \text { Range }\end{array}$ & $\begin{array}{l}1.99 \pm 0.60 \\
1.55-3.19\end{array}$ & $\begin{array}{c}2.87 \pm 0.86 \\
1.43-3.80\end{array}$ & $\begin{array}{l}3.19 \pm 0.87 \\
1.17-4.37\end{array}$ & 5.18 & $0.01 *$ \\
\hline $\begin{array}{ll}\text { SOD } & \mathrm{U} / \mathrm{ml} \\
\mathrm{X} \pm \text { SD } & \\
\text { Range } & \end{array}$ & $\begin{array}{c}3.92 \pm 0.72 \\
3.60-4.44\end{array}$ & $\begin{array}{l}4.08 \pm 0.40 \\
3.87-4.90\end{array}$ & $\begin{array}{c}4.39 \pm 0.37 \\
3.79-4.99\end{array}$ & 5.03 & $0.02 *$ \\
\hline
\end{tabular}


Post hoc test for table 5.

LSD

\begin{tabular}{|lll|l|l|l|}
$\begin{array}{l}\text { Dependent } \\
\text { variable }\end{array}$ & $\begin{array}{c}\text { job stress } \\
\text { level } \\
\text { I }\end{array}$ & $\begin{array}{c}\text { job stress } \\
\text { level } \\
\text { J }\end{array}$ & $\begin{array}{c}\text { Mean } \\
\text { Difference } \\
\text { (I-J) }\end{array}$ & Std.error & P value \\
\hline MDA & Mild or no & Moderate & -0.87 & 0.48 & 0.07 \\
& Mild or no & Severe & -1.2 & $\mathbf{0 . 3 7}$ & $\mathbf{0 . 0 0 3}$ \\
\hline MDA & Moderate & Severe & -0.32 & 0.32 & 0.392 \\
\hline SOD & Mild or no & Moderate & -0.16 & 0.21 & 0.459 \\
& Mild or no & Severe & $-\mathbf{0 . 4 7}$ & $\mathbf{0 . 1 6}$ & $\mathbf{0 . 0 0 7}$ \\
\hline SOD & Moderate & Severe & -0.31 & 0.16 & 0.06 \\
\hline
\end{tabular}

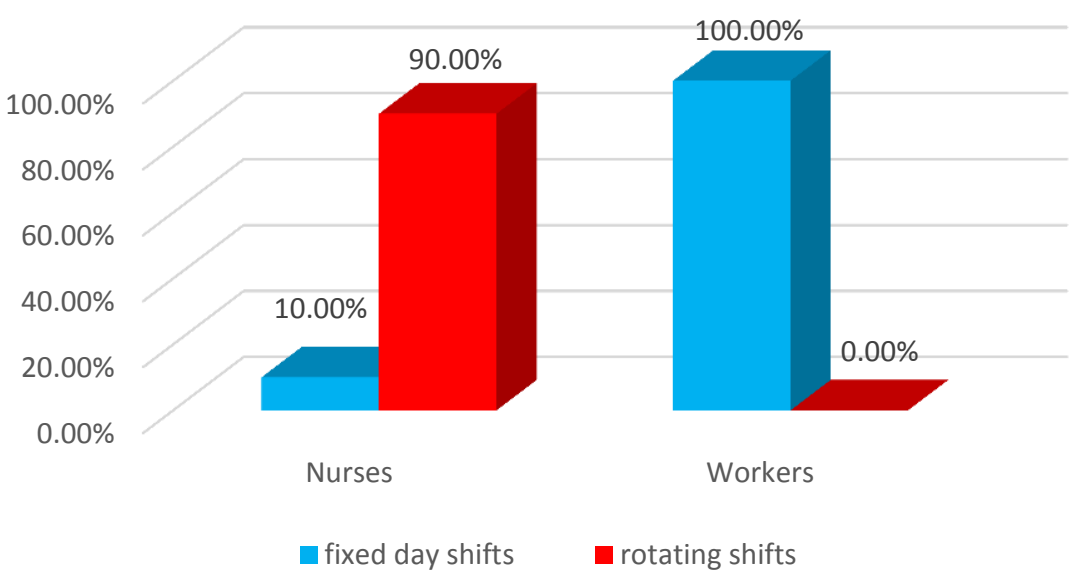

Figure 1. Difference in work shift among both studied groups. 


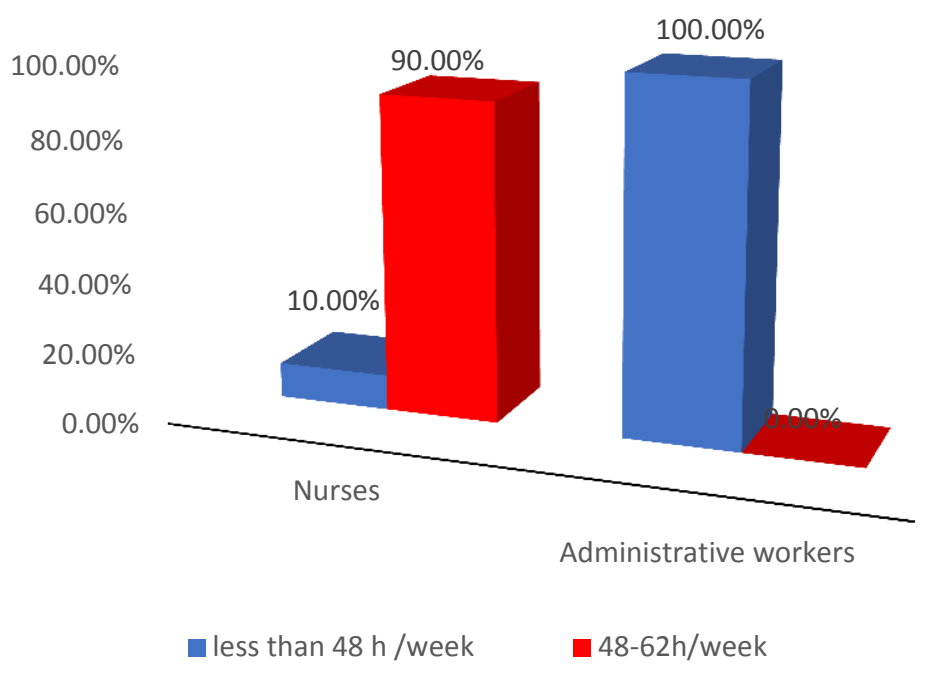

Figure 2. Difference in working hours /week among nurses and administrative workers

\section{DISCUSSION}

Job stress is much more important in the field of healthcare, because healthcare services delivery is very laborious and risky. To achieve quality, efficiency, effectiveness, and equity in these types of services, conditions must be appropriate and accompanied by the reduction of stress among nurses.

Reactive oxygen species (ROS) are formed in the human body in the cytosol, mitochondria, lysosomes, peroxisomes and plasma membranes under both physiological and pathological conditions, their levels can be increased by stress situations such as occupational stress [19].

Demand Control model of Karasek cleared that high job demand and low control are main sources for job stress. Job demand is unavoidable stressor that leads to many negative consequences and connects directly to job dissatisfaction [20]. The result of present study illustrated that there were high statistical differences between nurses and their controls as regard job demand, job control and Job strain as nurses suffered from high job demand $(\mathrm{X} \pm \mathrm{SD}=17.50 \pm 3.7)$ with low job control $(\mathrm{X} \pm \mathrm{SD}=14.87 \pm 7.69)$ causing higher job strain score $(\mathrm{X} \pm \mathrm{SD}=1.53 \pm 0.76)$ compared to $\mathrm{X} \pm \mathrm{SD}$ of $(5.52 \pm 1.33)$, $(33.3 \pm 3.59)$ and $(0.16 \pm 0.04)$ respectively among their controls (Table 1). This in agreement with previous studies [21] in Egypt, [22] in Brazil, [23] in Iran, [24] in Belgium and [25] in Ethiopia, this can be contributed due to inadequate nurse to patient ratios, difficult work schedules with long hours of work, frequent shifts, lack of control, lack of resources, inadequate salaries, and poor career. Furthermore, Xie et al. [26] cleared that Chinese nurses working at Shanghai hospitals scored high job strain scores due to type of hospital, as they were working at high ranking large hospitals that were in continuously competition at a high level in comparison to other hospitals.

From the present study, $85.0 \%$ of nurses suffered from stress compared to $22.5 \%$ in their controls, where $65.0 \%$ and $20.0 \%$ of the studied nurses suffered from severe and moderate stress compared to $7.5 \%$ and $15.0 \%$ respectively among their controls, while $15.0 \%$ of nurses had mild or no stress compared to $77.5 \%$ in their controls with high statistically significant differences (Table2). This is comparable to other studies conducted in different Egyptian governorates as El Dahshan and Hafez [27] study conducted at Alexandria University Hospitals where approximately $80 \%(40 / 50)$ of studied nurses had high stress level while $12 \%$ (6/50) had low stress level. Moustafa and Gaber [28] also illustrated that $88.3 \%$ of staff nurses at ZUHS were highly stressed and this was contributed to frequent dealing with and dying, high workload and uncertainty concerning treatment. Moreover, Zaki [29] study carried out among psychiatric nursing working at mental health hospitals in Cairo, where the majority of psychiatric nurses (87.8\%) felt highly stressed due to patients' demand.

This high prevalence of stress among nurses can be explained by the health care system in 
Egypt facing multiple challenges in improving health status of all Egyptians as inadequate resources, inefficient health services delivery, insufficient salaries and incentives. Additionally, the health facilities' infrastructure (building, furniture and maintenance) is deteriorating that increasing stress over nurses. [30]

The current study results indicated that the most significant predictors for job stress in this study were nurses servicing more than 10 patients /shift, working in Surgery, ICU and Emergency departments followed by being female nurse, working more than 48-60hours /week and having rotating shifts Table 3.

This is in agreement with previous studies as Fang and Hung [31] study conducted among Taiwanese nurses found that being female nurses with working hours of 48 hours or more per week were significant predictors of job stress. In addition, Al-Makhaita et al. [32] indicated that the following factors being female, presence of work shifts, and working in Surgical and Emergency department were found to be independently and significantly predictable factors of job stress among nurses in Saudi Arabi. Moreover, SAMAEI et al. [33] study conducted in the public hospitals in the city of Babol in Iran revealed that being female, long weekly working hours and rotating shift work system able to predict the occupational stress of the nurses. In contrast, Khrais et al. [34] indicated that male nurses were experiencing higher stress level than females, this can be contributed to that men have many social commitments to think about; such obligations put them in more stressful situations than females.

The present study revealed a high statistically significant difference among both nurses group and their controls as regard level of MDA and statistically significant difference as regard level SOD that both biomarkers were higher among nurses than their controls Table 4. Moreover, both levels of MDA, [X \pm SD (range): $3.19 \pm 0.87$ (1.174.37) $\mu \mathrm{mol} / \mathrm{ml}]$ and SOD, $[\mathrm{X} \pm \mathrm{SD}$ (range): $4.39 \pm 0.37(3.79$ - 4.99) $\mathrm{U} / \mathrm{ml}]$ were significantly higher among nurses with severe stress compared to nurses with moderate and mild or no stress Table 5.
Only few studies have assessed the relation between job stress, burnout and oxidative stress. From these studies, in consistent with our study, Casado et al. [35] found an association between elevated MDA level and job stress which enhanced the formation of excessive free radicals, and lipid peroxidation in workers of a prehospital emergency service. Also, Casado et al. [19] reported significantly higher SOD activity and MDA level detected in nurses who scored significantly higher burnout subscales that causing more reactive oxygen generation associated with higher antioxidant activity among intensive care unit nurses. Furthermore, Casado et al. [36] reported higher SOD activity and MDA concentrations in palliative care workers who had evening and night shifts and scored significantly higher levels of job stress.

In Egypt, Salem and Ebrahem [4] proved that job stress depending on effort reward model was associated with elevated MDA level among nurses at Menoufia university hospitals.

Further studies supported the relation between job stress and oxidative biomarkers using biomarkers rather than blood as Inoue et al. [37] proved that Job stress was associated with increased level of urinary oxidative biomarker 8-hydroxy-2' deoxyguanosine (8-OHdG) levels in women, but not in men, Another study conducted in japan by Takaki [38] indicated that job stress depending on demand control model was significantly positive associated with urinary (8-OHdG) after adjustment for covariates in women.

Further studies depending on relation between work shift and oxidative biomarkers [39-40] suggesting that work shift associated with higher MDA and lower SOD level causing higher oxidative stress indices that is in contrast to this study where both MDA and SOD level increased, as our study showed slight elevation of MDA that followed by an elevation of SOD to achieve the adaptation while work shift studies showing marked higher MDA level that can't be adapted and blood samples in work shift studies were taken twice from participants before and 
immediately after work shift and long working hours that may make difference.

\section{CONCLUSION}

This study concluded that nursing is highly demanding and stressful profession as high percentage of staff nurses experienced high level of job stress that associated with high levels of blood oxidative biomarkers that represented a significant problem and a major challenge to occupational health of nurses.

\section{RECOMMENDATION}

For managers, Recognizing and understanding job stress and the job-related stressors of nursing may help nurse managers to implement strategies to reduce nurse's stress and at the same time to improve patient outcomes.

For nurses, Nurses need continuing education about stress management, maintaining a supportive workplace environment and multidisciplinary teamwork.

Conflict of interest: No conflict of interest

Funding process: No funding

\section{REFERENCE}

1- Magnavita N , Fileni A. Work stress and metabolic syndrome in radiologists: first evidence. La radiologia medica 2014; 119(2): 142-148.

2- Asadi H., Garavand A., Khammarnia M, Abdollahi, M. B. The sources of work stress among nurses in private hospitals in shiraz. Journal of Health Management and Informatics 2017; 4(3): 71-75.

3- Shafaghat T, Rahimi Zarchi M K, Kavosi Z. Occupational stress and how to confront it: A case study of a hospital in Shiraz. Hospital Practices and Research 2018; 3(2):64-68.

4- Salem E.A and Ebrahem S.M. Psychosocial work environment and oxidative stress among nurses. Journal of occupational health2018; 60(2):182-191.

5- Elden N.M.K, Rizk, H.I.I and Wahby G. Improving Health System in Egypt: Perspectives of Physicians. Egyptian Journal of Community Medicine 2016; 34(1):45-58

6- Gheshlagh R, Parizad N, Dalvand S, Zarei M, Farajzadeh M, Karami M. et al. The prevalence of job stress among nurses in Iran: A meta-analysis study. Nursing and Midwifery Studies 2017; 6(4) :143-148.

7- Zorov D.B, Juhaszova M, Sollott S.J. Mitochondrial reactive oxygen species (ROS) and ROS-induced ROS release. Physiological reviews 2014; 94(3):909-950.
8- Lawson M, Jomova K, Poprac P, Kuča K, Musílek K and Valko M. (Free Radicals and Antioxidants in Human Disease): Nutritional Antioxidant Therapies:Treatments and Perspectives 2017;1(1): 283-305. Springer, Cham.

9- Aschbacher K, O'Donovan A, Wolkowitz O.M, Dhabhar F.S, Su Y and Epel E. (Good stress, bad stress and oxidative stress: insights from anticipatory cortisol reactivity. Psychoneuroendocrinology 2013; 38(9):1698-1708.

10- Khan M. A and Baseer A. Increased malondialdehyde levels in coronary heart disease. JPMA. The Journal of the Pakistan Medical Association 2000; 50(8): 261-264.

11- Karasek R, Brisson C, Kawakami N, Houtman I. Bongers P., Amick, B. The Job Content Questionnaire (JCQ): an instrument for internationally comparative assessments of psychosocial job characteristics. Journal of occupational health psychology 1998; 3(4): 322-355

12- ISMA. International Stress Management Association of United Kingdom, stress questionnaire 2013; Available at : http://isma.org.uk/wpcontent/uploads/2013/08/StressQuestionnaire.pdf

13- Ohkawa H, Ohishi N, Yagi K. Assay for lipid peroxides in animal tissues by thiobarbituric acid reaction. Anal Biochem 1979; 95(2):351-359

14- Nishikimi M, Rao N.A and Yagi K. The occurrence of superoxide anion in the reaction of reduced phenazine methosulfate and molecular oxygen. Biochemical and biophysical research communications 1972; 46(2):849-854.

15- Kakkar P, Das B and Viswanathan P. A modified spectrophotometric assay of superoxide dismutase. Indian J. Biochem. Biophys 1984; 21(2):130-132.

16- Gonzales R, Auclair C, Voisin E, Gautero H. Dhermy D. and Boivin P. Superoxide Dismutase, Catatase, and Glutathione Peroxidase in Red Blood Cells from Patients with Malignant Diseases. American Association for Cancer 1984; 44(9): 41374139.

17- IBM Corp. IBM SPSS Statistic for windows, version 22.0. Armonk, NY 2013; IBM Corp.

18- World Medical Association Declaration of Helsinki Ethical Principles for Medical Research Involving Human Subjects: Bull. World Health Organ. Epub, 2001;74: 373374.

Available

at: 
https://www.ncbi.nlm.nih.gov/pubmed/11357 217

19. Casado Á, Castellanos A, López-Fernández M.E. Ruíz R. Aroca C.G., Noriega F. Relationship between oxidative and occupational stress and aging in nurses of an intensive care unit. Age 2008; 30(4):229-236

20- Bani-Hani M. A, Hamdan-Mansour A. M, Atiyeh, H. M, and Alslman, E.T. Theoretical Perspective of Job Demands Correlates among Nurses: Systematic. Health 2016; 8(1):1744-1758.

21- Mohamed N. A and Mohamed S. A. Impact of job demand and control on nurses' intention to leave. Life Science Journal 2013; 10(2): 223-229.

22- Theme Filha M.M, Costa M.A.D.S, Guilam M.C.R. Occupational stress and self-rated health among nurses. Revista latinoamericana de enfermagem 2013; 21(2):475483

23- Barzideh M, Choobineh A and Tabatabaee H. Comparison of job stress dimensions in Iranian nurses with those from other countries based on the demand-controlsupport model. Journal of health sciences and surveillance system 2014; 2(2): 66-71.

24- Trybou J, Germonpre S, Janssens H, Casini A., Braeckman L., Bacquer D.D. et al., Jobrelated stress and sickness absence among Belgian nurses: A prospective study. Journal of nursing scholarship 2014; 46(4): 292-301.

25- Nuru N, Zewdu F, Amsalu S and Mehretie Y. Knowledge and practice of nurses towards prevention of pressure ulcer and associated factors in Gondar University Hospital, Northwest Ethiopia. BMC nursing 2015; 14(1): 34-42.

26- Xie Z, Wang A, Chen B. Nurse burnout and its association with occupational stress in a cross-sectional study in Shanghai. Journal of advanced nursing 2011; 67(7): 1537-1546.

27- El Dahshan M.E and Hafez S.K. Effect of Job-Related Stressors on Nurses' Job Satisfaction in El-Shatby Maternity University Hospital, Alexandria, Egypt. The Egyptian Journal of Community Medicine 2014; 301(1922):1-18

28- Moustafa, M. S and Gaber, M. A. Relationship between Organizational Culture, Occupational Stress and Locus of Control among Staff Nurses at Zagazig University Hospitals in Egypt. Int J Health Sci Re s 2015; 5(1):206-218.

29- Zaki R. Job Stress and Self-Efficacy among Psychiatric Nursing Working in Mental
Health Hospitals at Cairo, Egypt. Journal of Education and Practice 2016; 7(20):103-113.

30- Abd ELLatief O.K, Mahfouz E.M, Ewis A.A and Seedhom A.E. Burnout syndrome among healthcare providers in different hospitals in Minia City. Egyptian Journal of Occupational Medicine 2018; 42(1): 21-32.

31- Fang, L., \& Hung, C. H. Predictors of married female nurses' health. Workplace health \& safety 2014; 62(11): 447-455.

32- Al-Makhaita H. M., Sabra, A. A and Hafez, A. S. Predictors of work-related stress among nurses working in primary and secondary health care levels in Dammam, Eastern Saudi Arabia. Journal of family \& community medicine 2014; 21(2): 79-84.

33- SAMAEI, S.E., AHMADI, O., SOLEIMANIAN, S.S., KALANTARI, M., AKBARIAN, N., SADEGHI, M. et al., Evaluating the status of occupational stress and identifying the related risk factors in nurses in Babol: A cross-sectional study. International Journal of Occupational Hygiene 2018; 10(2):1-6.

34- Khrais H, Higazee A, Zeinhom M, Wahab A. , Diab S. Impact of Orgaet al., (2018): Impact of Organizatinal Support on Nursing Job Stressors: A Comparative Study. Health Science Journal 2018; 12(4):1-6.

35- Casado Á, De Lucas N, López-Fernández E, Sánchez A , Jimenez J.A. Lipid peroxidation, occupational stress and aging in workers of a prehospital emergency service. European Journal of Emergency Medicine 2006; 13(3):165-171.

36- Casado Á, Castellanos A, López-Fernández M, Ruiz R, Imedio E, Castillo C, et al. Determination of oxidative and occupational stress in palliative care workers. Clinical chemistry and laboratory medicine 2011; 49(3):471-477.

37- Inoue A, Kawakami N, Ishizaki M, Tabata M, Tsuchiya M, Akiyama M, et al. Three job stress models/concepts and oxidative DNA damage in a sample of workers in Japan. Journal of psychosomatic research 2009; 66(4): 329-334.

38- Takaki J. Associations of job stress indicators with oxidative biomarkers in Japanese men and women. International journal of environmental research and public health 2013; 10(12): 6662-6671.

39- Ulas T, Buyukhatipoglu H, Kirhan I, Dal M.S, Eren M.A, Hazar A, et al. The effect of day and night shifts on oxidative stress and anxiety symptoms of the nurses. Eur Rev Med Pharmacol Sci 2012; 16(5): 594-599. 
40- Faraut B, Bayon V and Léger D. Neuroendocrine, immune and oxidative stress in shift workers. Sleep medicine reviews 2013; 17(6): 433-444.

Mohamed, A., El-Saadawy, M., Soliman, N., EL-shafei, D. Relation between Job stress and How to cite 围 Oxidative stress Biomarkers among Nurses in Zagazig University Hospitals. Zagazig University Medical Journal, 2020; (758-768): -. doi: 10.21608/zumj.2019.15216.1376 